\title{
Oral Proton Pump Inhibitor for Treatment of Congenital Chloride Diarrhea
}

Hee Cheol Jo, M.D., Jong Seo Yoon, M.D., Joo Young Jang, M.D., Young Bae Sohn, M.D.*, Jang Hoon Lee, M.D., Hae Il Cheong, M.D. , and Moon Sung Park, M.D.

Department of Pediatrics and Medical Genetics*, Ajou University Hospital, Ajou University School of Medicine, Suwon, Korea Department of Pediatrics ${ }^{\dagger}$, Seoul National University Children's Hospital, Seoul National University College of Medicine, Seoul, Korea

\section{ABSTRACT}

Congenital chloride diarrhea (CCD) is a rare autosomal recessive disease, which is characterized by electrolyte absorption defect due to impaired function of the $\mathrm{Cl}^{-} /$ $\mathrm{HCO}_{3}{ }^{-}$exchanger in the ileum and the colon. Its main features are profuse watery diarrhea, high fecal chloride concentration, and failure to thrive. Profuse watery diarrhea characterized by a high concentration of chloride in stools results in hypochloremia, hyponatremia, and dehydration with metabolic alkalosis. Early detection and therapeutic intervention can prevent life-threatening symptoms of CCD and growth failure. Recently, several therapies, such as proton pump inhibitors and butyrate, have been suggested for amelioration of diarrhea. Here, we report a case of CCD in a preterm male infant who was successfully treated with an oral proton pump inhibitor.

Key Words: Congenital chloride diarrhea, Alkalosis, SLC26A3, Proton pump inhibitor, Omeprazole

\section{INTRODUCTION}

Congenital chloride diarrhea (CCD) is a rare autosomal recessive disease, which is characterized by defective absorption of chloride in the intestine. In 1945, two cases of this disease, which presented with congenital diarrhea and metabolic alkalosis, were described for the first time by Gamble and Darrow ${ }^{1,2)}$. To date, more than 250 CCD cases have been reported worldwide ${ }^{3)}$. The incidence in Finland is approximately 1:30,000 to 1:40,000, accounting for approximately one-fifth of the reported cases ${ }^{3)}$. Higher incidence $(>1: 20,000)$ was reported in patients from Poland, Kuwait, and Saudi Arabia ${ }^{3,4)}$. The incidence of CCD in Korea and other East Asian countries has not been evaluated thus far and only a few CCD cases have been reported ${ }^{5}$. CCD is caused by mutations in the solute carrier family 26 member 3 gene (SLC26A3) located on chromosome 7q31, which encodes the transmembrane $\mathrm{Cl}^{-} / \mathrm{HCO}_{3}{ }^{-}$exchanger present in the apical membrane of the ileum and the $\operatorname{colon}^{3,6,7)}$. A total of 55 mutations in SLC26A3 have been identified
Received: 7 August 2015

Revised: 13 September 2015

Accepted: 29 September 2015

Correspondence to:

Jang Hoon Lee, M.D.

Department of Pediatrics, Ajou

University Hospital, Ajou University

School of Medicine, 164, World cup-

ro, Yeongtong-gu, Suwon 16499,

Korea

Tel: +82-31-219-5168

Fax: +82-31-219-5169

E-mail: neopedlee@gmail.com

Copyright(c)

By Korean Society of Neonatology.

All right reserved.

This is an Open-Access article distributed under the terms of the Creative Commons Attribution Non-Commercial License (http://creativecommons.org/licenses/ by-nc/4.0), which permits unrestricted non-commercial use, distribution, and reproduction in any medium, provided the original work is properly cited. 
worldwide thus $\mathrm{far}^{8)}$. The majority of mutation types are single nucleotide substitutions (55\%), followed by small deletions/ insertions or their combinations (38\%), large deletions (5\%), and insertions $(2 \%)^{8}$. These mutations result in defective absorption of $\mathrm{Cl}^{-}$and secretion of $\mathrm{HCO}_{3}{ }^{-}$in the intestine, leading to $\mathrm{Cl}^{-}$rich watery diarrhea ${ }^{3,6,7)}$. Because of this intestinal loss of ions and fluid, the patient experiences hypochloremia, hyponatremia, and dehydration. These conditions activate the reninangiotensin system, which causes both hypokalemia and metabolic alkalosis ${ }^{3)}$. Accurate diagnosis and correction of electrolyte imbalance will restore normal growth and development with favorable prognosis. Recently, several drugs such as proton pump inhibitors and butyrate have been suggested as effective and successful therapies for diarrhea ${ }^{3,9,10)}$. Here, we report a case of CCD in a preterm male infant with a mutation in the SLC26A3 gene who was successfully treated by oral administration of the proton pump inhibitor omeprazole.

\section{CASE REPORT}

A 30-year-old woman with a history of one pregnancy and one abortion was referred to our hospital at an estimated gestational age of 32 weeks with abdominal pain and polyhydramnios. Previous fetal ultrasonography revealed polyhydramnios and a dilated fetal bowel loop. Hence, the newborn was suspected to have congenital small bowel obstruction or atresia (Figure 1). Since fetal ultrasonography at estimated 34week gestational age showed severe progression of polyhydramnios and persistence of the dilated small bowel condition in

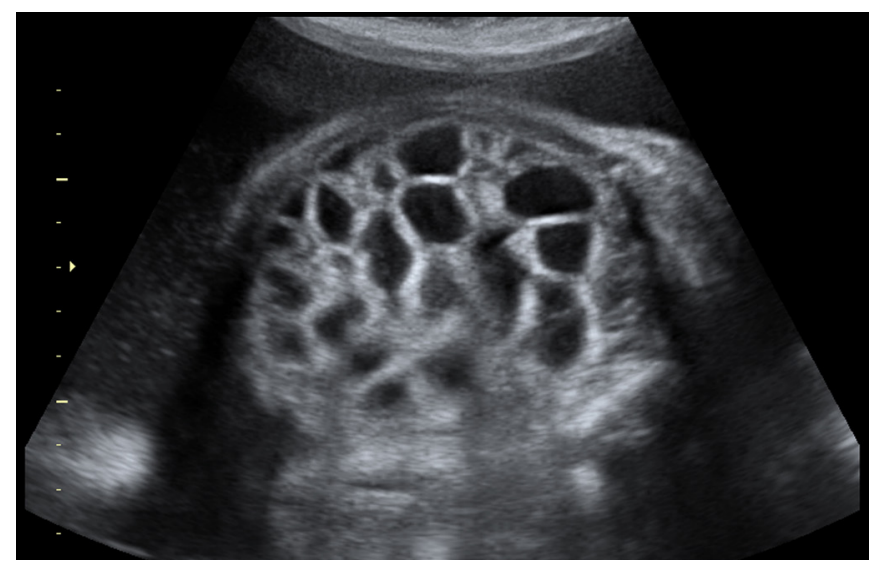

Figure 1. Prenatal ultrasonography of a male fetus (estimated gestational age: $34^{+1}$ weeks) showing dilatation of bowel loops. the fetus, a male newborn was delivered by a cesarean section at estimated $34^{+7}$ week gestational age with a birth weight of $2,800 \mathrm{~g}$. The Apgar score was 8 and 9 at 1 and 5 minutes after birth, respectively. Physical examination revealed a soft and distended abdomen with normal bowel sounds. The newborn did not exhibit hepatomegaly, splenomegaly, or palpable mass. Other physical examinations reported normal results and newborn's vital signs were stable after birth. Abdominal X-ray demonstrated dilatation of bowel loops. However, there was no evidence of small or large bowel obstruction as shown by abdominal ultrasonography and water-soluble contrast study of the gastrointestinal tract. After the abdominal distension was reduced by inserting an orogastric tube for 3 days, the newborn received enteral nutrition. He was discharged at 9 days of age.

One week later, the newborn infant was admitted to hospital for icteric skin color and lethargic condition at 17 days of age. Urine-like watery diarrhea about 10 times per day with insufficient sucking was also observed. In laboratory tests, hyponatremia (serum sodium, $124 \mathrm{mmol} / \mathrm{L}$ ), hypochloremia (serum chloride, $75 \mathrm{mmol} / \mathrm{L}$ ), and metabolic alkalosis (blood $\mathrm{pH}, 7.69$ and base excess, $14.2 \mathrm{mmol} / \mathrm{L}$ ) were identified. Abdominal X-ray showed a severe distension of bowel loops when compared to the condition seen during initial observations (Figure 2). Since CCD could be caused by single gene mutation, genetic testing was performed to confirm the diagnosis. After obtaining an informed consent from patient's parents, peripheral blood

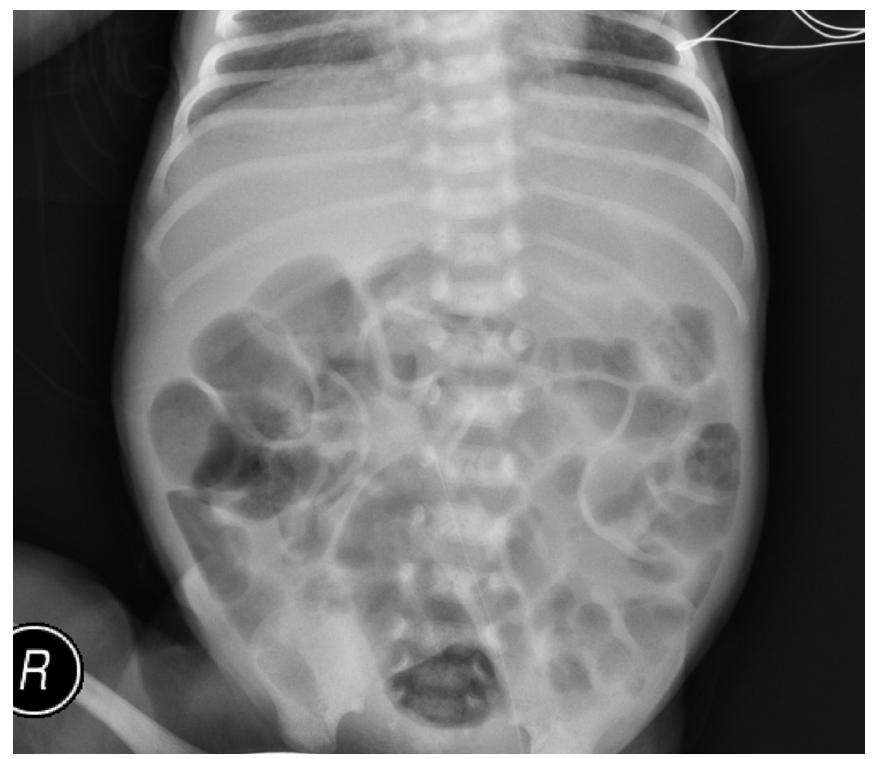

Figure 2. Plain abdominal radiographs of the same patient during the second admission showed marked dilatation of bowel loops with air. 
was collected from the patient and his parents for deoxyribonucleic acid (DNA) extraction. Sequence analysis of the SLC26A3 gene identified a homozygous transition ( $\mathrm{G}$ to $\mathrm{T}$ ) in the splice acceptor site of intron 18 (c.2063-1G>T). In the familial study, patient's father and mother were found to be heterozygous carriers of c.2063-1G>T (Figure 3). After confirming the diagnosis of CCD, oral omeprazole $2 \mathrm{mg} / \mathrm{kg} /$ day was added to fluid concomitantly with sodium supplementation at one month of age. Two days after the start of omeprazole treatment, the frequency of stool passages decreased from 10 to 4 times per day. Intravenous fluid therapy for electrolyte correction was discontinued and oral treatment with $3 \mathrm{mEq} / \mathrm{kg} /$ day sodium chloride $(\mathrm{NaCl})$ was initiated. At the time of discharge, the patient was able to take all formula feeds by mouth and serum electrolytes were stable after oral $\mathrm{NaCl}$ administrations. After discharge, his serum electrolytes were within the normal range even though the amount of oral $\mathrm{NaCl}$ was reduced subsequently. At the same time, omeprazole treatment was continued and adjusted for his increased weight.

At 9 months of age, the patient continued to receive $2 \mathrm{mg} / \mathrm{kg} /$ day omeprazole and electrolyte supplementation with $1 \mathrm{mEq} /$ $\mathrm{kg} /$ day $\mathrm{NaCl}$. His weight and height were $9.1 \mathrm{~kg}\left(50^{\text {th }}\right.$ percentile) and $74.7 \mathrm{~cm}\left(25^{\text {th }}\right.$ percentile), respectively. He had normal growth and development without obvious electrolyte imbalance. We planned to make the transition to usual solid food without an additional salt replacement.

\section{DISCUSSION}

Clinical characteristics of CCD include watery diarrhea in the intrauterine phase. Prenatal signs of CCD, such as polyhy- dramnios and a dilated bowel loop of the fetus, are visible on prenatal ultrasonography even in the end of the second trimes$\mathrm{ter}^{3)}$. Other complications include preterm birth, severe polyhydramnios requiring therapeutic amniocentesis, and unnecessary surgery in neonates ${ }^{3 \text { ) }}$. It is necessary to rule out intestinal obstruction, such as small bowel atresia or congenital megacolon, particularly when newborns present with delayed passage of meconium and distended abdomen ${ }^{3,11)}$.

The infant may have profuse watery diarrhea, which can be mistaken for urine, for several days. Due to this persistent watery diarrhea, dehydration and excessive weight loss will develop in patients with CCD. Metabolic alkalosis and electrolyte imbalance will be usually revealed in laboratory investigations. If left untreated, these conditions can be fatal, as metabolic alkalosis and electrolyte imbalance can lead to arrhythmia and severe dehydration $^{3)}$. Untreated conditions may also result in developmental retardation, chronic kidney disease, and male subfertility $^{3)}$. The clinical characteristics and long-term outcomes of CCD cases reported in Korea are summarized in Table $1^{12-16)}$.

Diagnosis of CCD is based on the measurement of high fecal chloride ( $>90 \mathrm{mmol} / \mathrm{L})$ and acidic $\mathrm{pH}^{3)}$. High concentration of fecal chloride is still sufficient to confirm the diagnosis. Currently, genetic analysis is available for the detection of CCDrelated SLC26A3 mutations and a total of 55 mutations have been reported ${ }^{8)}$. In Korea, genetic analysis results of 8 CCD patients have been published, and it was suggested that c.2063$1 G>T$ mutation could have been a founder mutation in Korean population ${ }^{5)}$. Our case also demonstrated the presence of the homozygous c.2063-1G>T mutation in our patient confirming the above notion that it could be a genuine founder mutation.

From the therapeutic point of view, salt substitution therapy is the standard CCD treatment, while the management of acute
(A)



(C)

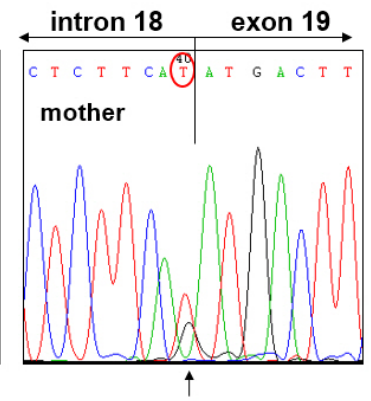

Figure 3. DNA sequence analysis of SLC26A3. (A) The patient had a homozygous transition at the splice acceptor site of intron 18 (c.2063-1G>T). (B) The patient's father and (C) mother were found to be heterozygous carriers of c.2063-1G $>\mathrm{T}$ (black arrow). 
Table 1. The clinical characteristics of the patients with congenital chloride diarrhea in Korea

\begin{tabular}{|c|c|c|c|c|c|c|c|c|c|}
\hline Source & Sex & $\begin{array}{c}\text { Gestational } \\
\text { age } \\
\text { (wks) }\end{array}$ & $\begin{array}{c}\text { Body } \\
\text { weight } \\
\text { (kg) }\end{array}$ & $\begin{array}{c}\text { Age of } \\
\text { diagnosis }\end{array}$ & Symptoms & Gene mutation & Treatment & $\begin{array}{l}\text { Duration of } \\
\text { follow-up }\end{array}$ & $\begin{array}{l}\text { Long-term } \\
\text { prognosis }\end{array}$ \\
\hline $\begin{array}{l}\text { Seo et al. }^{12)} \\
(1998)\end{array}$ & $\mathrm{F}$ & $36^{+4}$ & 3.5 & 3 months & $\begin{array}{l}\text { Chronic diarrhea } \\
\text { Lethargic condition }\end{array}$ & No description & Electrolyte replacement & 2 years & Favorable \\
\hline $\begin{array}{l}\text { Yoon et al. }^{13)} \\
(2003)\end{array}$ & $\mathrm{F}$ & $36^{+4}$ & 2.9 & 21 days & $\begin{array}{l}\text { Dilated abdomen } \\
\text { Chronic diarrhea }\end{array}$ & No description & Electrolyte replacement & 5 months & Favorable \\
\hline $\begin{array}{l}\text { Yim et al. } \\
(2012)\end{array}$ & M & 33 & 2.9 & 1 day & $\begin{array}{l}\text { Dilated abdomen } \\
\text { Chronic diarrhea }\end{array}$ & No description & Electrolyte replacement & 40 days & No description \\
\hline $\begin{array}{l}\text { Seo et al. }{ }^{16)} \\
(2013)^{*}\end{array}$ & M & $32^{+2}$ & 2.1 & 6 month & $\begin{array}{l}\text { Failure to thrive } \\
\text { Developmental delay }\end{array}$ & No description & Electrolyte replacement & 19 months & Unfavorable \\
\hline
\end{tabular}

* These two cases were twins.

dehydration and electrolyte imbalance during acute gastroenteritis or other infections is also necessary ${ }^{3)}$. The combination therapy with both $\mathrm{NaCl}$ and potassium chloride $(\mathrm{KCl})$ via the oral or intravenous route will protect against common CCD complications. The optimal dosage of chloride ranges from 6 to $8 \mathrm{mmol} / \mathrm{kg} /$ day in infants and from 3 to $4.4 \mathrm{mmol} / \mathrm{kg} /$ day in older children ${ }^{3,17}$.

Several therapies for diarrhea have been recently suggested in several cases. Omeprazole, a proton pump inhibitor, has been found to reduce watery diarrhea ${ }^{10)}$. Omeprazole decreases intestinal chloride loss by protecting endogenous chloride stores and by reducing the amount of chloride presented in the intestinal tract ${ }^{10)}$. Butyrate, a short-chain fatty acid, was also used to alleviate watery diarrhea through the activation of a parallel $\mathrm{Cl}^{-} /$butyrate and $\mathrm{Na}^{+} / \mathrm{H}^{-}$exchanger ${ }^{18)}$. In addition, cholestyramine decreased watery diarrhea symptoms to a certain extent, but its therapeutic action was moderate and transient ${ }^{3)}$.

There have been several reported cases of CCD that were successfully treated with omeprazole. Fuwa et al. ${ }^{19)}$ used omeprazole and butyrate for reducing watery diarrhea and their patient displayed normal growth without electrolyte supplementation. Pieroni et al. ${ }^{9)}$ described a CCD patient who received long-term omeprazole, which maintained serum electrolyte balance without $\mathrm{NaCl}$ and $\mathrm{KCl}$ supplementation. In our case, we also found that omeprazole strongly reduced watery diarrhea symptoms and corrected electrolyte imbalance. However, close monitoring of the efficacy of and adverse reactions associated with omeprazole is necessary because its utility and safety as an anti-diarrheal have not been sufficiently verified in CCD patients thus far. Because no official guidelines for omeprazole use in CCD patients have been published to date, we are planning manage diarrhea with omeprazole maintenance therapy and carefully monitor electrolyte imbalance and symptom severity. In conclusion, we have reported a case of CCD with a SLC26A3 mutation, which was successfully treated with omeprazole according to suggestions in the literature.

\section{REFERENCES}

1) Darrow DC. Congenital alkalosis with diarrhea. J Pediatr 1945;26:519-32.

2) Gamble JL, Fahey KR, Appleton J, MacLachlan E. Congenital alkalosis with diarrhea. J Pediatr 1945;26:509-18.

3) Wedenoja S, Hoglund P, Holmberg C. Review article: the clinical management of congenital chloride diarrhoea. Aliment Pharmacol Ther 2010;31:477-85.

4) Hoglund P, Auranen M, Socha J, Popinska K, Nazer H, Rajaram U, et al. Genetic background of congenital chloride diarrhea in high-incidence populations: Finland, Poland, and Saudi Arabia and Kuwait. Am J Hum Genet 1998;63:760-8.

5) Hong J, Seo JK, Ko JS, Cheong HI, Choi JH, Lee JH, et al. Congenital chloride diarrhea in Korean children: novel mutations 
and genetic characteristics. Eur J Pediatr 2013;172:545-50.

6) Moseley RH, Hoglund P, Wu GD, Silberg DG, Haila S, Chapelle A, et al. Downregulated in adenoma gene encodes a chloride transporter defective in congenital chloride diarrhea. Am J Physiol 1999;276:G185-92.

7) Hoglund P, Holmberg C, Sherman P, Kere J. Distinct outcomes of chloride diarrhoea in two siblings with identical genetic background of the disease: implications for early diagnosis and treatment. Gut 2001;48:724-7.

8) Wedenoja S, Pekansaari E, Hoglund P, Makela S, Holmberg C, Kere J. Update on SLC26A3 mutations in congenital chloride diarrhea. Hum Mutat 2011;32:715-22.

9) Pieroni KP, Bass D. Proton pump inhibitor treatment for congenital chloride diarrhea. Dig Dis Sci 2011;56:673-6.

10) Aichbichler BW, Zerr CH, Santa Ana CA, Porter JL, Fordtran JS. Proton-pump inhibition of gastric chloride secretion in congenital chloridorrhea. N Engl J Med 1997;336:106-9.

11) Shamaly H, Jamalia J, Omari H, Shalev S, Elias N. Congenital chloride diarrhea presenting in newborn as a rare cause of meconium ileus. J Perinatol 2013;33:154-6.

12) Seo JL, Jung WC, Kim KT, Kim YS, Lee SW, Cho Y, et al. A case of congenital chloridorrhea. Korean J Perinatol 1998;9:43-9.

13) Yoon SK, Kim EY, Moon KR, Park SK. A case of congenital chloride diarrhea in premature infant. Korean J Pediatr 2003; 46:308-11.

14) Lee ES, Cho AR, Ki CS. Identification of SLC26A3 mutations in a Korean patient with congenital chloride diarrhea. Ann Lab Med 2012;32:312-5.

15) Yim SM, Jo YS, Jang DG, Lee JH, Lee G. Congenital chloride diarrhea. Korean J Obstet Gynecol 2012;55:573-7.

16) Seo KA, Lee NM, Kim GJ, Yun SW, Chae SA, Lim IS, et al. Congenital chloride diarrhea in dizygotic twins. Pediatr Gastroenterol Hepatol Nutr 2013;16:195-9.

17) Hihnala S, Hoglund P, Lammi L, Kokkonen J, Ormala T, Holmberg C. Long-term clinical outcome in patients with congenital chloride diarrhea. J Pediatr Gastroenterol Nutr 2006;42:369-75.

18) Canani RB, Terrin G, Cirillo P, Castaldo G, Salvatore F, Cardillo $\mathrm{G}$, et al. Butyrate as an effective treatment of congenital chloride diarrhea. Gastroenterology 2004;127:630-4.

19) Fuwa K, Hosono S, Nagano N, Munakata S, Fukamachi R, Okada T, et al. Japanese neonate with congenital chloride diarrhea caused by SLC26A3 mutation. Pediatr Int 2015;57:e11-3. 